\title{
Clariant Opens Global Competence Centre
}

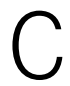

lariant recently opened its new

global innovation centre for chemical research and process technology in Frankfurt, Germany. The Clariant Innovation Centre (CIC), a 100 million euro investment, is based at the Industriepark Höchst and is equipped with application laboratories for several business units and state-of-the-art analytical laboratories. It will also house the departments for Intellectual Property Management and New Business Development. As a global hub, it will ensure the coordination of Clariant's world-wide R\&D network, which includes centres across Europe, North America, Brazil, Japan, India and China. The new facility covers a total surface area of 36,000 square metres and will house around 500 employees from R\&D and supporting business

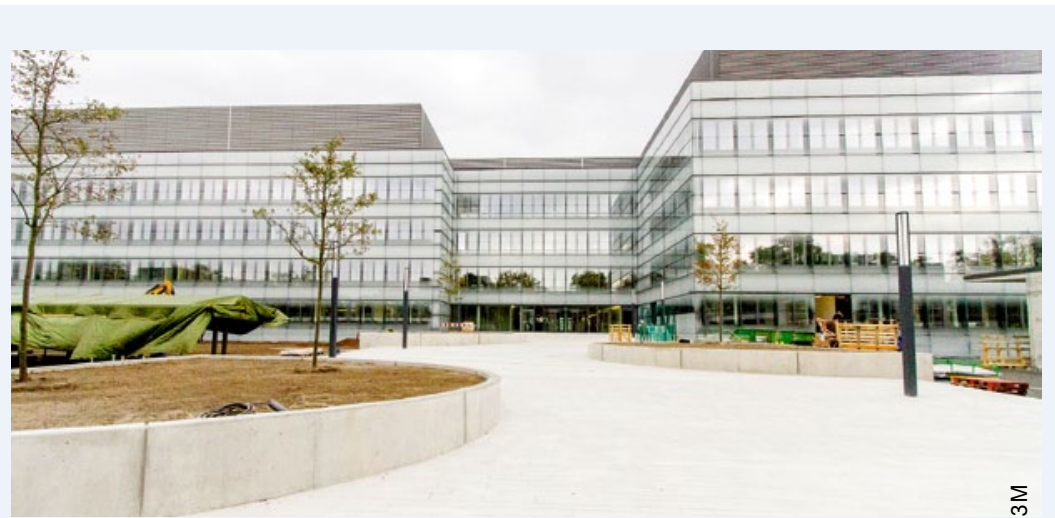

The specialty chemicals company Clariant has invested 100 million euros in the construction of a new innovation centre.

\section{M Earns German Sustainability Award}

$3 \mathrm{M}$ is one of the top three companies to win an award in the category "Resource Efficiency" among the 600 applicants for the 2013 German Sustainability Award.

3 M Germany was cited for setting ambitious goals to reduce its ecological footprint in the entire value chain, according to the jury. The judges said that the company considers the question of how to use resources as economically as possible in new developments. They added that innovations of 3M have the aim, wherever possible, of enabling the customer to operate more efficiently.

The jury rated 3M Germany high in the resource efficiency category because of its comprehensive approach. The judges said that, in the entire life cycle of the products, appropriate measures are implemented - from design to procurement, use, disposal and recycling.

"This award makes me proud," said Reza Vaziri, managing director, 3M Germany. "It makes me happy that we succeed again and again in developing new technologies while fulfilling our responsibilities toward mankind and the envi-

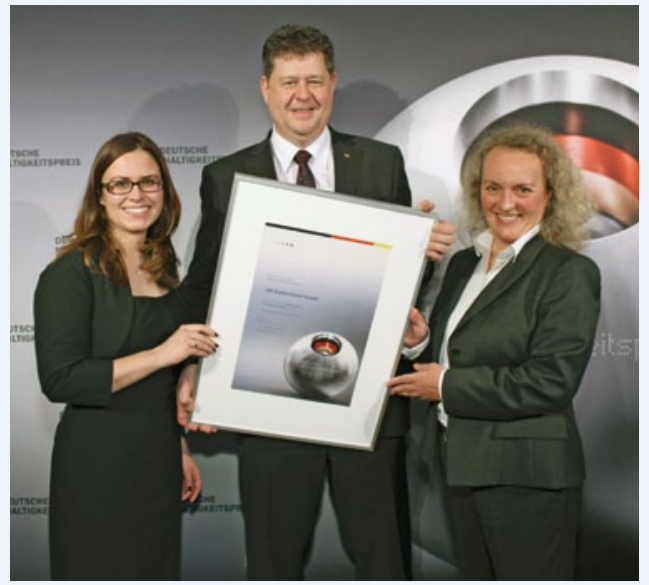

The award for exemplary resource protection was accepted by Silvia Havasi, General Manager Corporate Marketing, Sales \& Communications, Manfred Pufahl, Environmental Health \& Safety Manager and Gabriele Baucke, Manager Sustainability Corporate Communication, 3M Germany (from I. to r.)

ronment." According to Vaziri, 3M has the strong belief that only those companies that manage to combine the power of innovation with sustainability will be able to be successful in the long term. Since 1995, 3M has been setting new ambitious goals every five years with the aim of continuously improving its sustainability. For example, its sustainability goals set to be achieved by 2015 include lowering its worldwide use of solvents by 20 percent, cutting waste by 10 percent and reducing its energy consumption by 25 percent. 